\title{
TENTATIVAS PARA PROMOVER LA INDUSTRIA DEL JABÓN EN LA GALICIA SETECENTISTA
}

\author{
por \\ ANTONIO MEIJIDE PARDO
}

\section{Fomento de las fábricas de jabón *}

Ha sido en el fructífero reinado de Carlos III cuando comienzan a adoptarse firmemente las primeras providencias a fin de impulsar lo más posible la industria nacional del jabón, cuyo principal punto de arranque atañe entonces a las ciudades de Sevilla, Alicante y Elche, con el claro designio de eludir la habitual y masiva introducción del artículo extranjero. Tal decisión política de apoyo oficial a empresarios privados habría de permitir, con inmediatez, la proliferación en diversos puntos de la geografía peninsular de numerosas fábricas de jabón, cuyo gran impulso vióse muy propiciado por la extraordinaria abundancia de aceite, sosa y barrilla.

Entre las reales órdenes promulgadas por aquel celoso monarca con la finalidad de promocionar este tipo de industria cabe señalar las siguientes: En 1764 se concede libre facultad empresarial para establecer en cualquier punto del país factorías de jabón duro o blando, sin otra formalidad que la

* Siglas archivísticas: A.G.S., Archivo General de Simancas. A.H.N., Id. Histórico Nacional. A.H.P., Id. Histórico Provincial de Pontevedra. A.M.F., Archivo Municipal de Ferrol. A.M.S., Id. Municipal de Santiago. A.R.G., Id. del Reino de Galicia. A.U.S., Id. de la Universidad de Santiago. B.N.M., Biblioteca Nacional.

"CUADERNOS DE ESTUDIOS GALLEGOS", Tomo XXXIX, Fascículo 104, Santiago 1991. 
de asegurar la paga de derechos reales por sus dueños, a los cuales se otorgan valiosas franquicias. En 1769 se dispensa a los fabricantes el derecho de tanteo, por coste y costas, sobre la sosa o barrilla que necesitan para esta industria. Y en 1771 se autoriza el transporte por mar de aceite, sosa y barrilla sin abonar mayor impuesto que el realizado por tierra, siempre que dichos productos se conduzcan a bordo de naves de bandera nacional ${ }^{1}$.

Las franquicias dispensadas por la Monarquía prosiguen en ejercicio con Carlos IV. En 1793 se libera de derechos al jabón transportado de un puerto a otro a bordo de buques nacionales. En 1795, con el objeto de impedir se perjudicasen entre sí los fabricantes, se establece normativa con respecto al tributo de millones que debían satisfacer los fabricantes por consumo de aceite, barrilla y demás ingredientes. En 1800 se permite la venta de manufactura al por mayor y por menor al pié de las factorías, quedando así liberado el fabricante de la oposición que para su venta solían encontrar "a título de los abastos en los pueblos donde se hallan establecidas dichas fábricas"2.

Observamos que fruto de esta protección gubernativa la producción nacional de jabón alcanzaba ya a finales del siglo casi 60.000 quintales por año. Unas 30 provincias contaban con numerosas fábricas de diversas clases de jabón (conocidos comercialmente con las denominaciones de duro o de piedra, blando, de sosa, de aceite de oliva, de Sevilla, de Castilla, etc.).

Aunque persistía destacando Andalucía sobre las demás regiones, comienza ahora a disputarle la primacía el reino de Valencia, con un registro de 163 factorías del blando y seis del duro; las primeras dispersas por Castellón, Segorbe, Murviedro. Valencia, Alcira, Alicante, Alcoy, etc.; y las segundas instaladas principalmente en Murviedro y Elche. Los precios del jabón blando oscilaban, in situ, desde 30 a 36 reales por arroba, y los del duro alrededor de 40 reales $^{3}$. Año tras año prosperaba la industria del jabón en el ámbito levantino, debido sustancialmente a la extraordinaria riqueza en sales alcalinas, siendo estimada la barrilla por los agrónomos coetáneos como la mejor de Europa ${ }^{4}$.

1 A.G.S., C.S. Hacienda. Registros, libs. 202 (97-92), 210 (140-142), 241 (409411 y 415), 242 (75)

A.H.N., Consejos, libs. 1514 (doc. 66) y 1520 (doc. 57).

Reales Cédulas, núms. 209 y 247.

2 A.G.S., Rentas. Partidos, leg. 949, doc. 14 ago. 1793.

A.H.N., Hacienda, libs. 6019 (fol. 277) y 6104 (doc. 129).

${ }^{3}$ Correo mercantil de España y sus Indias, pág. 203, núm. 25, 26 sep. 1793

${ }^{4}$ A finales de siglo afincáronse en Alicante, Cartagena, Lorca, Murcia y Aguilas negociantes franceses, genoveses, y algún maltés, para consagrarse al lucrativo negocio de la exportación de barrilla. Ya en 1785 solía despachar el puerto de Cartagena, por ejemplo, un promedio anual de 130.000 quintales de sosa, en su mayor parte al mercado europeo.

"CUADERNOS DE ESTUDIOS GALLEGOS", Tomo XXXIX, Fascículo 104, Santiago 1991. 


\section{El consumo de jabón en Galicia}

La importación de jabón nacional o extranjero ha significado para Galicia una permanente y considerable fuga de caudales, sobre todo a partir de mediados del siglo XVIII, pues con anterioridad se desconocía prácticamente su comercio, en particular en el ámbito de la ruralía ${ }^{5}$. Los arrieros maragatos solían concurrir en gran número a puertos gallegos para provistarse de pescado, y luego transportaban en el tornaviaje crecida carga de jabón importado para su venta en el mercado interior.

Sarmiento, Somoza de Monsoriú y otros tratadistas dieciochescos han puesto de relieve hasta qué punto era Galicia tremendamente deficitaria en jabón. Los suministros foráneos comportaban, dentro de su habitual comercio pasivo, un renglón considerable, por lo que mucho lamentaron que no existieran fábricas de esta manufactura tan necesaria.

Al tratar sobre el comercio del aceite y de la barrilla --productos básicos para la fabricación-- nos dejó testimonio Sarmiento en su ms. titulado Historia natural de Galicia (1756) de cómo era "infinito el dinero que los maragatos extraen de Galicia a título de xabón y aceite". Y, con su peculiar grafismo, puntualizaba en otro texto que "loza, vidrio, jabón y aceite son las cuatro polillas que chupan de Galicia mucho dinero" 6 . Asimismo, denuncia el ilustre benedictino el precio exorbitante a que se vendía en el mercado regional por la arriería maragata la arroba de jabón; esto es, a no menos de 63 o 64 reales, cuando llegada esta mercancía foránea al puerto de Marín, por ejemplo, cotizábase a no más de 50 reales la arroba ${ }^{7}$.

Sarmiento había remesado en 1758 a su hermano Javier, por entonces ministro de marina de la provincia marítima de Pontevedra, semillas de barrilla alicantina, con la ambiciosa finalidad, sin duda, de introducir el cultivo de esta planta ramosa en ciertos parajes de Galicia, como en terrenos de la ría llamada de Junqueras (la de AresBetanzos), en la isla de Tambo (frente a Marín) o en la playa de A Lanzada ${ }^{8}$.

Casi un siglo después, propugnaría también el pontevedrés C. González Zúñiga por la aclimatación de dicha salsolácea en tieras incultas de Noalla, Portonovo, Sanxenxo y $\mathrm{O}$ Grove, donde, a su juicio, podría obtenerse una barrilla de tan buena calidad como la de Alicante 9 .

5 A.M.S., Consistorios, 1743 , fol. 40

${ }^{6}$ A.U.S., Sarmiento, ms. 599, docs. 18 dic. 1748 y 30 may. 1857.

B.N.M., Ibid., ms. 5666, fols. 129 y 131.

7 También los tragineros maragatos, tras adquirir en el citado puerto pontevedrés la arroba de aceite a 37 reales, hacía subir su venta a 53 o 54 reales en la Galicia del interior.

${ }^{8}$ A.U.S., Sarmiento, ms. cit., doc. 22 mar. 1758.

${ }^{9}$ En Descripción económica de la provincia de Pontevedra y mejoras de que es susceptible su industria agrícola, fabril y comercial, págs. 10 y 29 (Pontevedra, 
Por último, y con respecto al tráfico del jabón foráneo, no pasemos también por alto cómo no estuvo ajena a esta coyuntura comercial la masiva presencia en las principales plazas marítimas de Galicia de negociantes inmigrados de Cataluña (cuestión ésta a la que hemos dedicado más de un específico estudio monográfico). Así, los comerciantes catalanes afincados èn Ferrol, por ejemplo, solían vender en 1770 a 58 reales la arroba de jabón importado de su tierra nativa, frente a 60 reales que costaba el proveniente de Andalucía ${ }^{10}$.

Obvio es, pues, que expertos y tratadistas del XVIII hayan propugnado insistentemente la suma imperiosidad de erigir fábricas en Galicia de esta manufactura --"un abasto que es realmente de primera necesidad", comentará Larruga ${ }^{11}{ }^{-}$- como único medio de cancelar el lucrativo comercio que comportaba la masiva introducción del jabón foráneo.

\section{Tara y Godoy erigen'en Pontevedra la primera fábrica (1763).}

La primicial factoría de jabón duro o de piedra establecida en Galicia ha sido la instalada en términos de la parroquia de San Martiño de Salcedo, en una casa de Manuel Félix Montenegro ${ }^{12}$ sita en el lugar de Tablada, distante apenas un cuarto de legua de la villa de Pontevedra. En su corto espacio de vida estuvo manejada esta empresa por dos compañias.

Compusieron la primera sociedad Domingo de Tara, de "nación milanés, residente y del comercio de la ciudad de Lisboa", Miguel de Godoy y Francisco María Cantelo, éstos vecinos de Vigo y Pontevedra, respectivamente. Tara, como socio principal, fue el que aportó el capital necesario para emprender la fabricación y montaje del obrador.

La marcha y continuidad de esta empresa instalada en las cercanías de Pontevedra ha de discurrir con más pena que beneficio esperado. Pues todavía no cumplido un lustro de su creación se prevía su crisis. Aunque en algún testimonio coetáneo se alude a la poca pericia de los fabricantes, lo que más incidía negativamente en la futura suerte de esta fábrica era, sobre todo, la falta de recursos económicos para proveerse de aceite y barrilla, dos ingredientes básicos para la producción de manufactura, muy costosos en razón de hallarse sus bases de suministro muy distantes de

\footnotetext{
${ }^{10}$ A.M.F., Actas Ayuntamiento, fol. 64.

${ }^{11}$ En Memorias políticas y económicas sobre los frutos, comercio, fábricas y minas de España, págs. 296-298, vol. 44 (Madrid, 1799).

12 De familia hidalga y fortuna acomodada, Montenegro era "dueño y señor de la Casa y mayorazgos de la Tablada..." (A.H.P., Protocolos, leg. 1353, fols. 32-33, 1779).
} 
Galicia. Cabe indicar en relación al grave escollo que significaba la falta de fondos, que la firma Tara Godoy y Cía. se vió forzada a elevar ante la Junta de Comercio una representación atinente a los nuevos auxilios que requeríanse para salvar su empresa ${ }^{13}$.

En mayo de 1773 se constituye la llamada segunda compañia, limitada al término de cinco años, con el fin de poder solventar la crisis. Se incorporan ahora a la primera sociedad, constituída en el 63, dos nuevos socios: Pedro Antonio Reboredo, del que sabemos que era abogado y tuvo a su cargo por algún tiempo la Subdelegación en Galicia de la Renta de Salinas ${ }^{14}$, y José Moar, quien ejercía de oficial en la Contaduría provincial de la citada Renta ${ }^{15}$. Aportaron ambos a la nueva compañia sendos capitales de 23.000 y 13.000 reales, respectivamente. Se estipularon en la escritura de contrata de la sociedad, entre otras, las siguientes condiciones:

1) La dirección y el manejo técnico de la fábrica continuaría estando a cargo de Godoy.

2) Cantelo, como oficial de libros, se encargaba de llevar "la cuenta y razón diaria de todas las entradas y salidad de géneros, jabón, utensilios y más materiales; como también la correspondencia con los sujetos con quienes se hubiese de tratar para la compra y conducción de los mismos géneros y materiales".

3) Moar tendría por misión preferente la de fiscalizar, junto con Cantelo, las expresadas entradas y salidas. Y ambos tendrían en su poder las dos llaves del Arca de fondos de la sociedad.

$4^{\mathrm{a}}$. Por último, en septiembre de cada año habría de formar la compañía "avance y cuenta para saber el estado de la negociación, y sacar cada intesado las utilidades que le correspondiesen, sin que pudiera hacerlo del capital durante el término estipulado, a menos que por el mismo avance resultasen quiebras, que en este caso sería voluntad de cada socio retirarse o proseguir en la compañia"16.

Las fuertes desavenencias surgidas desde hacía tiempo entre los componentes de la sociedad abocarían a engorrosos litigios en 1776.

Observamos primeramente que el milanés Tara demandaba a sus asociados ante la Real Audiencia de Galicia. Declara en esta querella que debido a su condición de extranjero y "ser habitante en la Corte de Portugal, donde tiene sus negocios, nunca pudo lograr desde allí, que los más

13 A.G.S., C.S. Hacienda. Registros, lib. 210, fols. 140-142.

14 P.A. Reboredo poseía cuantiosísima fincabilidad rústica dispersa por las parroquias de Salcedo, Mourente, Lourizán, etc. (A.H.P., Protocolos, legs. 1351 y 1402).

15 A.H.P., Protocolos, leg. 1403, fol. 72 (1783).

16 A.H.P., Ibid., leg. 1375, fols. 88-89.

"CUADERNOS DE ESTUDIOS GALLEGOS", Tomo XXXIX, Fascículo 104, Santiago 1991. 
compañeros que de continuo corrieron con la administración de dicha fábrica, le dieren cuenta anual con arreglo a lo escriturado en los documentos, por mucho que lo solicitó; antes bien, procediendo con repetidas demoras y engaños, se la diferían para retener más tiempo sus caudales y aprovecharse de ellos en grave perjuicio suyo ..."17.

Por otra parte, también Reboredo y Moar pleitearon a la vez con Godoy y Cantelo. Pues viéndose descubiertos en sus respectivos capitales de 23.000 y 13.000 reales aportados a la sociedad, y sin conocer si ésta había generado ganancias o pérdidas, exigían se les diese cuenta formal del producto y efectos de la fábrica, de conformidad a la contrata de compañia que habían ajustado. Al no poder conseguir tal demanda recurren al Justicia de Pontevedra solicitando se "les apremiase por todo rigor de derecho". De su pedimento reproducimos estos pasajes:

"Que ahora de próximo, nos han diligenciado con una Real Provisión de Su Excelencia, los Señores del Real Tribunal de este Reyno, librada a pedimento de Dn. Domingo Tara, vecino de la Ciudad de Lisboa, para que le diésemos cuenta de la fábrica de xabón que de él y Dn. Miguel de Godoy establecieron en la feligresía de San Martín de Salcedo y Campo de la Tablada de ella, a cuya Compañía fuimos instado y persuadidos por el mismo Tara (...) Para mayor justificación de nuestra realidad, hacemos presentación de la propia cuenta, con la cual hacemos constar a vuesa merced tener cumplido por nuestra parte con lo que se nos manda por dicha Real Provisión, pero sin perjuicio de repetir y reclamar contra dicho Tara y los más que hubiera lugar, las quiebras del caudal que entramos en dicha Compañia, del que indebidamente ha usado convirtiéndolo en sus usos particulares y en pagar diferentes deudas contraídas, tanto en este Reyno como en el de Portugal, consumiendo y aniquilando los fondos de la propia fábrica y Compañía, hasta que hubo de quebrar enteramente"18.

El último dato que disponemos acerca de ambos contenciosos atañe al poder notarial otorgado por Godoy, Moar y Cantelo en Pontevedra, en febrero de 1777; del que se infiere cómo proseguía sub judice la resolución definitiva de tan complejo y engorroso litigio intraempresarial ${ }^{19}$.

Lo cierto es que esta modesta industria discurría en años sucesivos hacia su total ruina. Como "lo está demostrando la experiencia con el xabón que reparte tan malo", declárase en 1784, y lo subido de su precio en "las provincias algo distantes de su residencia", que llega a casi una peseta por libra ${ }^{20}$. Consignemos, finalmente, que en un informe presentado al Real Consejo por la compostelana Real Sociedad Económica de Amigos del País, se alude, de pasada, al deteriorado status que presenta-

17 A.R.G., Ibid., leg. cit., doc. 17 may. 1766, etc.

18 A.R.G., Ibid., leg. cit., doc. 22 may. 1776.

19 A.H.P., Protocolos, leg. 1351, fols. 33-34, 1777.

20 A.H.N., Consejos, leg. 1340 (22), fol. 8.

"CUADERNOS DE ESTUDIOS GALLEGOS", Tomo XXXIX, Fascículo 104, Santiago 1991. 
ba aquella empresa, por más que en ciertos años se hubiese alguna crecida ganancia, a pesar de la poca pericia de los fabricantes y tener que traer éstos todas las materias primas de Andaluciía y Levante. No fue posible, en definitiva, su continuidad. "Sus cortos fondos, mala administración, male fé de algunos comisionados y la desconfianza e inconstancia de algunos accionistas ...", concluía el informe de la Económica santiaguesa, terminaron por desacreditar decisivamente aquella empresa y abocaría a su total ruina en $1785^{21}$.

\section{El intento de Prina y Cía. en La Coruña (1768)}

Tres comerciantes de nacionalidad extranjera deciden formar sociedad mercantil, a principios del 68, con el exclusivo propósito de establecer en La Coruña una fábrica de jabón para "poder vender este artículo con beneficio del público por diez años..." Fúeron estos negociantes el italiano Angel Prina y los franceses Juan Mathias Maifren y Tomas Laval, avecindados los dos primeros en La Coruña y el último en Ferrol.

La titulada sociedad Prina y Cía. presentó ante la Junta de Comercio un memorial y pliego de condiciones. Además de la concesión de las habituales franquicias de índole fiscal sobre las materias e ingredientes precisos para elaborar la manufactura, solicitaba el privilegio privativo de que en la ciudad de La Coruña, y por el término de un decenio, "no se permita a otro alguno establecer fábrica de esta naturaleza".

La Junta de Comercio informará obstantivamente con respecto a la concesión por la Corona del importante privilegio exclusivo. El ente fabril que la firma Prina y Cía. pretende erigir, "no es de tal clase que por el bien del Estado empeñe a la dispensación de privilegios exorbitantes", sino que deben dispensarse a la proyectada fábrica coruñesa iguales franquicias que a las demás de su clase. Y, puntualiza la Junta de Comercio, de ningún modo "se ha de conceder franquicia alguna de las que no disfruten las fábricas de jabón de Castilla, ni tampoco el privilegio que solicitan, privativo y exclusivo por diez años, que a nadie se ha concedido en parte alguna"22.

Así, pues, por R.O. de 5 de julio de 1768, y de conformidad con el antecedente dictamen, se otorga licencia regia a los empresarios Prina, Maifren y Laval para poder establecer su proyectada factoría, con la franquicia de "la transportación por mar de los aceites, sosas y barrillas, que necesiten y consuman en ella, pagando sólo los derechos Reales que adeudarían estos géneros conducidos por tierra, con obligación de pre-

${ }^{21}$ A.H.N., Consejos, leg., cit., doc. 13 jul. 1785.
22 A.H.N., Hacienda, lib. 10.809, fol. 279, 1768.

"CUADERNOS DE ESTUDIOS GALLEGOS", Tomo XXXIX, Fascículo 104, Santiago 1991 
sentar tornaguías y de sujetarse a las demás providencias conducentes a evitar fraudes a la Real Hacienda..." Pero no han de gozar gracia alguna que "no disfruten las fábricas de jabón de Castilla, ni el privilegio exclusivo que pretenden los interesados"23.

Observaremos, consiguientemente, cómo no obtendría realidad ulterior el intento de Prina y asociados. Pues éstos desistieron de implantar dicha fábrica. Impelidos, sin duda, porque no se contemplaban con los suficientes recursos para dotar a su empresa de rentabilidad comercial y con visos de perdurabilidad, al tener que afrontar la muy costosa adquisición de primeras materias básicas, con sus bases de acopio tan distanciadas de La Coruña.

\section{La tentativa de Godoy y Torre en Betanzos (1771).}

Corría el otoño del 71 cuando otros dos negociantes se propusieron emprender la producción de jabón en la ciudad de Betanzos. Miguel de Godoy, (el mismo que años antes se asoció con Tara para establecer la fábrica pontevedresa ya estudiada) y Domingo de Torre, expusieron a la Junta de Comercio su interés por promover la elaboración de jabón, "con fuego y sin él, de mejor calidad y a precios más cómodos que el que ahora es preciso comprar de los extranjeros..."; por ser obvio que en Galicia no existen fábricas y de esta manufactura no puede surtirse debidamente, sino a un precio exorbitante, de la que "se hace en otras provincias de España, a causa de su costosa conducción, con crecidos portes por tierra, y de lo gravado que está la que se hace por mar..."24

En sesión plenaria celebrada el 3 de octubre por la Junta de Comercio, debatida la propuesta presentada por el consorcio Godoy-Torre, se acordó dar luz verde a la misma. Tras este favorable dictamen, con data 15 de noviembre se dió traslado al Intendente General de Galicia del competente despacho regio por el cual se otorga permisividad para poder erigir la proyectada factoría en términos de la ciudad de Betanzos. Y se dispensa a dichos empresarios "la facultad que han pedido para transportar por mar los aceites, sosa y barrilla que necesitan para su fábrica de jabón en Galicia, sin pagar más derechos que los que adeudarían aquellos frutos si los llevasen por tierra, siempre que la conducción se haga en embarcaciones de bandera española, y se observen las formalidades correspondientes de guías y tornaguías, para evitar fraudes a la Real Hacienda"25.

23 A.H.N., Ibid., lib. cit., fol. 375 .

24 A.G.S., C.S. Hacienda. Registros, libs. 241 y 245, fols. 243 y 422.

A.H.N., Hacienda, lib. 8028, doc. núm. 2443.

25 A.G.S., C.S. Hac. Registros, libs. 133 (38), 213 (259-260) y 242 (89).

Superintendencia. Rentas generales, leg. 1252, doc. 15 nov. 1771.

"CUADERNOS DE ESTUDIOS GALLEGOS", Tomo XXXIX, Fascículo 104, Santiago 1991. 
Posteriormente serían alzadas a la Corona dos nuevas peticiones por parte de Godoy y Torre. La primera, en 1773, atinente a que se les permitiese también transportar en buques de bandera extranjera el aceite y sales alcalinas. La segunda, en 1774, incumbe a la exención de derechos para el artículo elaborado y permiso para importar el llamado jabón pintado del mercado exterior ${ }^{26}$.

Los negociantes habían expresado a la Junta de Comercio la obstantiva circunstancia de hallarse a más de cien leguas de distancia las bases de suministro de aceite, sosa y barrilla, en razón de cosecharse estos productos, casi con exclusividad, en los reinos de Andalucía y Valencia. Coyuntura que incidía enormemente sobre el alto coste en la conducción por mar de dichas materias primas, a tenor de que los derechos de embarque y desembarco asciendan al $28 \%$. Esto es el motivo principal porque "se ven los naturales de Galicia en la precisión -seguimos a Larruga- de comprar el xabón a los extranjeros, de la calidad y a los precios que ellos quieran, en conocido detrimento del Real Erario por los caudales que se extraen fuera del Reyno". Además de arribar tan cargados de derechos reales, los citados simples habrían de abonar después los que se adeudan en la fábrica y satisfacer "otro pago del xabón fabricado que se saque para Reynos extraños". Por todo ello "se viene en conocimiento -concluían los empresarios- de que es imposible que el fabricante pueda sacar para estos costos, y de aquí nace la decadencia de este tráfico y el carecer la Real Hacienda de las utilidades que quedan insinuadas"27.

Así, pues, vemos cómo hubieron de desistir, finalmente, dichos negociantes de su loable intento. Porque temían que la factoría que proyectaban instalar en Betanzos, al carecer de posibilidades de una mínima rentabilidad comercial en la venta de la manufactura, estaría abocada al fracaso.

\section{Sinnot y Vico pretenden también erigir fábrica en Betan- zos (1783)}

A un decenio del fracasado proyecto de los negociantes Godoy y Torre, de nuevo se pretendió levantar una factoría jabonera en la ciudad de Betanzos. Fue promovida esta iniciativa por Pedro Sinnot, presbítero irlandés e hijo de un Director-fabricante de jabón, con la colaboración del betanceiro Ignacio Vico de Guerra Seijas, abogado y de familia "de bastante caudal y acreditada" 28 .

${ }^{26}$ A.G.S., C.S. Hacienda. Registros, lib. 245, fol. 246.

${ }^{27}$ E. Larruga, ob. cit., págs. 295-298, vol. 44.

${ }^{28}$ En 1776 Vico ingresó al tesoro 2.000 maravedíes en concepto de media annata para matricularse de abogado de los Reales Consejos (A.H.N., Consejos leg. 12136, doc. 9 ago. 1776).

"CUÁḊERNOS DE ESTUDIOS GALLEGOS", Tomo XXXIX, Fascículo 104, Santiago 1991. 
Fue en el estío del 83 cuando solicitan Sinnot y Vico permiso regio a fin de poder emprender la elaboración de jabón a base de emplear sebos y grasas en vez de aceite; para cuya empresa, y como socio capitalista, afianzaba el letrado de Betanzos la cantidad de 100.000 reales. Esfuerzan su pretensión en el hecho de existir en toda Galicia una sola fábrica de jabón duro -refiriéndose a la de Salcedo-, en la cual a causa de "ser el aceite poco y caro, y lo mismo la barrilla, sale a cerca de peseta cada libra"; en tanto que en su proyectada factoría, "aprovechando los sebos y grasas podrá el público obtener cada libra de jabón por la mitad de aquel precio, esto es, por 16 o 17 cuartos"29.

A tal efecto, el clérigo irlandés hacía llegar a manos del conde de Campomanes, Gobernador del Real Consejo, un amplio memorial con este pomposo título: Plan de una nueva Fábrica de xavón duro y de piedra, hecho sin azeite, ni barrilla, que propone establecer Dn. Pedro Sinnot, presbítero Yrlandés, en el Reyno de Galicia, como más adecuado para el fin, y conforme a su secreto. En este memorandum, de nítida tipología arbitrista, expresó a Campomanes lo que sigue:

(...) "Es deseo del Proponente, eclesiástico, de avanzada edad, que quiere dejar por obsequio a S.M. y en beneficio de la Nación Española que tanto estima, su secreto que la Ynglaterra conserva como una de las principales Columnas de sus Fábricas. Y tiene revelado muchas de sus experiencias y combinaciones a un vasallo de S.M. de su mayor confianza ${ }^{30}$, y de cuya habilidad se promete el Proponente el más feliz éxito, manejo y progresos, por no ser conveniente ni permitirlo su edad más operaciones que las privadas y propias del Arte. Y que enseñadas éstas al referido sujeto, las vaya extendiendo a voluntad de S.M. Finalmente, no siendo, como efectivamente no lo es, este Proyecto o nueva Fábrica de xavón de piedra muy costoso, y sí muy útil, como se puede considerar, espera el Proponente será del agrado de S.M. el admitir este sacrificio de su benevolencia, y el que se establezca y fomente para utilidad pública"31.

Por su parte, a poco más de un mes del antecedente escrito, observamos que con la misma finalidad dirigía Vico al ministro de Estado un memorial, excesivamente prolijo, bajo el epígrafe siguiente: Advertencias relativas al Plan de una Fábrica de xavón duro o de piedra, que en el Reyno de Galicia y Ciudad de Betanzos propone establecer Dn. Pedro Sinnot, y que considera indispensable Dn. Ignacio Vico, abogado del Colegio de esta Corte, si se atiende a la naturaleza y circunstancias del Proyecto, y se examina el citado plan. Transcribimos por curiosidad el texto de este escrito:

${ }^{29}$ A.H.N., Consejos, leg. 1340 (22), fol. 14.

${ }^{30}$ Refiérese a su consocio Vico.

31 A.H.N., Estado, leg. 3182, exp. 99, doc. 3 jul. 1783. 
"No hay duda que el pensamiento de Dn. Pedro Sinnot, de fabricar e introducir en el Reyno de Galicia el nuevo xavón de piedra, es uno de los más útiles que se pueden proporcionar en beneficio y comodidad de aquellos naturales, así por respecto a las primeras materias o ingredientes de la composición, las que por su abundancia natural se pueden muy bien llamar privativas de aquel terreno, por exemplo, la manteca, el helecho, toxo, como por ser este género, en su línea, de primera necesidad en todo el Reyno.

La experiencia que Dn. Ignacio Vico tiene, y de algunas noticias particulares de diferentes ramos de industria que ha podido adquirir en los viajes que ha hecho al Reyno de Francia y mucha parte de Italia, además de su asistencia a las lecciones botánicas de este Corte y fuera de ella, le contribuyen con mayores luces e ilustración a la materia de que se trata y para poder informar con conocimiento del país por ser hijo de él.

La larga amistad de muchos años con Dn. Pedro Sinnot, no sólo ha dado origen a muchas conferencias propias del Proyecto, sino también a combinar todos los ingredientes que constituyen su composición. El helecho en primer lugar es una yerba más común en casi toda Galicia que en Aragón el tomillo; las mantecas, sebos, etc. no admiten disputa. Atendidas todas estas circunstancias, y la propiedad del sitio que por ahora debe elegirse, se puede tener muy bien por el más conveniente la Ciudad de Betanzos, así por la Casa que cita el Plan, como por ser la Capital más inmediata y proporcionada para todos los ingredientes que se necesitan (...).

La viva intención de Dn. Pedro Sinnot en mejorar el Reyno de Galicia con su particular secreto es muy apreciable una vez que vaya acompañada de dos precisas circunstancias: la primera será con la elección de un buen socio, si puede ser patricio experto e instruído del propuesto intento y que posee el arte de saber congeniarlo con sus patriotas, suavizando su mal humor para con un bienhechor extranjero, de estado sacerdotal y de edad avanzada; la segunda, por consiguiente, será que el asociado tenga la autoridad competente al nuevo Establecimiento, y que estas facultades sean privativas de esta superioridad, pues de intervenir la Audiencia de Galicia se complicarán las quejas o recursos, de modo que todo se resolverá en interrupciones y dilaciones en perjuicio de los progresos del Proyecto, gastar caudales y aventurar la utilidad del secreto.

Parece necesario, cuando se trata de nuevos Establecimientos, antes de ponerse en práctica, no perder de vista las reglas de economía y la seguridad del sujeto que ha de manejar los caudales. Por aquéllas se logra no gravar en más de lo preciso las fábricas, y por esto se consigue la buena inversión y administración de ellas. Dn. Pedro Sinnot, enterado de estas y otras razones que naturalmente se infieren, ha instado y persuadido continuamente a Dn. Ignacio Vico, su amigo, para que secundase sus intenciones, pues además de las Leyes de que hace profesión, tuvo por gusto particular la curiosidad y trabajo de acomodar con la Abogacía la instrucción de los elementos de Matemáticas y algunas nociones de Chímica; principios muy adecuados al Establecimiento que se propone, además de poder afianzar con efectos de su casa o de un hermano suyo que tiene en la Ciudad de La Coruña y en su Audiencia la cantidad de cien mil o más reales, como es público.

Pero como adherido Vico a las solicitudes de Dn. Pedro Sinnot por sola la amistad, sin embargo de la utilidad tan grande que va a resultar a Galicia, su patria, decretado que sea el Establecimiento, y que el estado de éste y su edad piden por necesidad un buen báculo firme que lo sostenga, sería proceder ligeramente y con perjuicio de sí mismo, respecto de tener que abandonar su bufete, y de hacerse más gravoso a su casa, sólo por acompañar, ayudar y mejorar la comodidad de sus Regnícolas sin la menor recompensa, por no ser el Establecimiento, en sus principios, susceptible de 
muchos sueldos y salarios, se ha resistido siempre constantemente a esta alianza. Así por lo dicho como por no incurrir en ningún género de sospecha, hasta que la ocasión proporcionó el arbitrio de poder hacerse el Abogado Vico útil a su Nación, sin detrimento tanto de su carrera cuanto de la misma Fábrica, confiesa con la verdad y claridad que le es natural, que jamás ha pensado trillar el camino de Corregidor, ni menos haber importunado a nadie para su acomodo hasta ahora, y la solicitud que parece va a establecerse es más hija de la ocasión que de la industria. Ocasión es hallarse vacante el Corregimiento de Betanzos. Industria es servir a Dn. Pedro Sinnot en lo que de Vico pretende. Beneficio es el procurar a la Nación un alivio sin ningún gasto. Y economía, finalmente, es servir de balde en lo principal de la Fábrica.

Si esto es pensar a lo natural o con inteligencia, V.S.Y. lo juzgará. Pues si algún objeto tenía Vico con este modo de pensar, sería únicamente el que si sus méritos fuesen suficientes la Superioridad le otorgase el acomodo a que regularmente aspiran todos los que trabajan con la debida preferencia o el bien público al particular. Y el abrazar dicho Corregimiento sólo será con la principal mira de trabajar, promover y fomentar el nuevo Proyecto del xavón de piedra, sin otro interés por esto que el de ser atendido en sus ascensos a proporción de sus progresos y pública utilidad. Por cuyo motivo es evidente que sin el requisito de no tener que entender en el expresado Establecimiento, de ningún modo separadamente pretende el referido Corregimiento, y aún en el caso de conferírsele deberán acompañarle las facultades reales relativas e independientes, como va expuesto. Con igual ingenuidad confiesa Vico y le parece que Dn. Pedro Sinnot se acompaña de un sujeto, sea que fuere, en quien no concurran las circunstancias ya citadas, aunque no duda del Establecimiento duda mucho sí de sus progresos.

Que es cuanto puedo decir a V.S.Y., cuya vida guarde Dios muchos años que ha menester. Madrid y Agosto 18 de 1783. B.L.M. de V.S.Y. Ignacio Vico"32.

He aquí las cuatro franquicias más valiosas requeridas por el consorcio Sinnot-Vico para llevar a efecto la implantación de la fábrica:

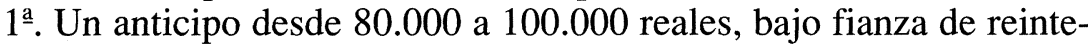
gro, a cuenta del fondo de espolios y vacantes del arzobispado de Santiago.

2a . Cesión del edificio construido en Betanzos para futura sede del Archivo del Reino de Galicia para instalar en él la fábrica de jabón.

3 . Concesión a Vico de la jurisdicción privativa de la industria y sus pertenencias con la única subordinación al Real Consejo.

4. . Que a efectos de "adelantar la fábrica" fuese nombrado Vico para el cargo vacante de Alcalde de la ciudad de Betanzos por el tiempo que "fuera del agrado de S.M." y merecer luego ser Corregidor en propiedad.

Observamos cómo transcurrían los meses sin respuesta alguna por parte del Real Consejo a dichas demandas. Tal demora motivó que, en abril del 84, decidiesen Sinnot y Vico elevar, ahora al Rey, una representación en súplica de autorización regia y concesión de las especiales franquicias solicitadas para su proyectada fábrica. El texto del extenso escrito alzado al monarca decía así:

${ }^{32}$ A.H.N., Estado, leg. cit., exp. cit., doc. 18 ago. 1783.

"CUADERNOS DE ESTUDIOS GALLEGOS", Tomo XXXIX, Fascículo 104, Santiago 1991. 
"Señor

Don Pedro Sinnot, Presbítero, y Don Roque Ignacio Vico, natural del Reyno de Galicia y abogado de los Colegios de la Audiencia de Galicia y de esta Corte, puestos a los R.P. de V.M. dicen:

Que siendo una de las principales máximas recibidas fundamentales de la industria el desterrar la ociosidad y disipar las tenaces preocupaciones que causa una impertinente ignorancia originada de la poca actividad, y de un gusto exquisito a la indolencia, si este epíteto merecen aquellos infelices que por un corrosivo influjo de una opinión general en el estado llano de todo el Reyno de Galicia a la deserción de su Patria, con abandono dilatado cuando no perpetuo de sus casas, padres, mujeres e hijos, por falta no de una total ocupación y sí movidos de una mal entendida ambición de mejorar su fortuna, catequizados por una bandera de capataces que aunque vasallos de V.M. no se sabe cuál sea su cuartel, sirviéndoles de pretexto para la recluta la indigencia, la falta de fábricas, y ninguna manufactura (...)

No precisan estos principios y los demás que naturalmente se infieren, a proponer a V.M. el Plan de una fábrica de xabón duro, a la inglesa, que intentan los suplicantes establecer en aquel Reyno y Ciudad،de Betanzos, adaptada por todas las circunstancias al más reflexionado sistema de aquel clima y a sus producciones naturales (...)

Se ha comunicado este intento al Ilmo. Sr. Conde de Campomanes. Se ha formado expediente en el Consejo sobre las experiencias conducentes, y practicadas que fueron y se aprobó por útil y de ley el nuevo xabón que los suplicantes solicitan introducir en el Reyno de Galicia, con la Real aprobación, protección y privilegios correspondientes que sean del agrado de V.M.

Entre las muchas utilidades que este xabón duro producirá en aquel Reyno, preferible sin duda al común que se usa, son: $1^{\mathrm{a}}$, el ahorro de aceite; $2^{\mathrm{a}}$, el de barrilla, planta cáustica que destruye y abrasa las tierras que la producen si la diligencia se descuida; 3a , podrá tener el público más barata esta especie, de una mitad de lo que actualmente paga por libra; y, últimamente, con este nuevo xabón la ropa, así de lino como de lana, se limpia mucho mejor con igual cantidad, y se evitan las coladas y lexías tan perjudiciales que las queman (...)

De los Reynos de España, el de Galicia es el más escaso de las dos especies de aceite y barrilla. Y por esta razón sólo en toda su extensión se conoce una fábrica de xabón común que reparte, tan malo, como su subido precio de casi a peseta por libra en las provincias algo distantes de su residencia ${ }^{33}$. Por otra parte, es este Reyno el más abundante de lencería y de todo género de vegetales, de cuyas cenizas ha de componerse el nuevo xabón, cuajado con los sebos y grasas que allí se hacen tan abundantes como propias para este pensamiento (...)

Como para semejante establecimiento es indispensable una casa cómoda y proporcionada, tiene el Reyno de Galicia una en la Ciudad de Betanzos que ha sido costeada para Archivo de los papeles de su Audiencia. Lo que no se ha verificado por las nulidades que padece y la que, por esta razón, se halla desocupada y sin destino, y bastante maltratada por falta de cuidados y habitación. De manera que si la voluntad de V.M. se digna destinarla para esta nueva fábrica por el tiempo que fuese de su Real agrado, se repararía, bien que a costa del mismo Reyno, subsistiría, y no se aventuraría la pérdida de 800.000 y más reales que se han desembolsado por este edificio (...)

Los suplicantes consideran necesarios de ochenta a 100.000 reales, cuya cantidad podrán suplir por ahora los espolios y vacantes del Arzobispado de Santiago. De

\footnotetext{
${ }^{33}$ Referíanse a la fábrica instalada a extramuros de Pontevedra.
} 
cuya cantidad está pronto Dn. Roque Ignacio Vico a dar las correspondientes fianzas de reintegro dentro del tiempo o término conveniente, o hipotecando en caso necesario, para mayor seguridad, bienes sitos y propios de su Casa (...)

No pueden menos que hacer presente a V.M. que esta fábrica por su naturaleza y circunstancias, necesita la Real aprobación y amparo del Soberano, a fin de que tenga toda la completa perfección, y que se les dé la jurisdicción privativa de la fábrica y de todo lo a ella perteneciente, con subordinación al Consejo. Lo que, siendo del agrado de V.M., podrá componerse pasando el Corregidor de Betanzos por estar paralítico al inmediato Corregimiento de la Ciudad de La Coruña y éste a uno de los que están vacantes o para vacar, y conferir el de Betanzos al suplicante por el tiempo que fuere del agrado de la Real piedad y como por vía de comisión, en tanto que la citada fábrica se planifica y toma un decente incremento; pues con esta autoridad podrá hacer Vico en el asunto algunos más progresos, que en otra forma serán difíciles o moralmente imposibles por los estorbos que consigo trae todo nuevo Proyecto. En cuyo caso, y méritos si los tuviere, espera el suplicante de V.M. se dignará declararle por Corregidor en propiedad con arreglo a los últimos Reales decretos, y se quedarán con la dirección y manejo de dicha fábrica ambos suplicantes, siempre que los efectos correspondan a la idea que se propone.

A V.M. suplican que la cathólica Real piedad de V.M. se digne aprobar este establecimiento, con todo lo demás que va especificado. Gracia que espera merecer de V.M. Madrid y abril 26 de 1784. Pedro Sinnot. Roque Vico"34.

Antes de aprobarse por la Corona resolución en firme sobre el antecedente memorándum, acordó la alta cámara nacional dar traslado del mismo a las Sociedades Económicas de Madrid y Santiago, a fin de que estas prestigiosas instituciones dictaminaran debidamente "lo que se les ofreciere y pareciere en el asunto"; así como requerir igualmente del Intendente General de Galicia informase acerca de las circunstancias personales que concurrían en Sinnot y en Vico; puesto que, declárase por el Real Consejo, "un clérigo y un abogado, aunque pueden saber mucho, pueden ignorar el modo de hacer jabón económicamente"35.

El informe elaborado por la Sociedad Económica de Amigos de País, de Santiago, remítiase en el estío del 85 al conde de Campomanes. Mostrábase enteramente favorable a las pretensiones y personales circunstancias de ambos recurrentes. Reproducimos a continuación la casi totalidad del dictamen.

"Exmo. Señor:

El celo de esta Sociedad, animado con la confianza que experimenta en la benignidad del Rey, no se satisface sólo con informar favorablemente acerca de la fábrica que pretenden establecer dn. Pedro Sinnot y dn. Roque Vico, y que S.M. se digna someter a examen, sino que tan honorífico mandato le presenta una ocasión muy oportuna para suplicar a S.M., por medio de V.E., se digne dispensar su Soberana protección a una fábrica que juzga tan útil y necesaria a esta país.

${ }^{34}$ A.H.N., Consejos, leg. 1340, exp. núm. 22, fols. 6-13.

${ }^{35}$ A.H.N., Estado, leg. 3182, exp. núm. 99, docs. 4 y 6 may. 1784. 
Siendo el jabón un género de primera necesidad y del que tiene que surtirse enteramente Galicia de las provincias más remotas, no hay duda que le resultarán grandes ventajas de su fábrica, principalmente si se hallan en su suelo todos los ingredientes que necesita para su composición (...)

La ciudad de Betanzos, donde se pretende establecer, parece a esta Sociedad un paraje muy proporcionado al efecto. El pueblo corto, y con edificio sin destino y a propósito para el caso; el país barato, lleno de pobreza, que se podría emplear útilmente; abundancia de todos los vegetales precisos para la fábrica. Por otra parte, su inmediación a La Coruña y El Ferrol, puertos de grande comercio, llenos de tropa, marinería y jornaleros empleados en los Arsenales, podrá proporcionar a la fábrica un pronto despacho de sus primeras producciones, en cuyo favorable principio no poco consiste la fortuna de estos establecimientos (...)

La Sociedad está informada de que los dos pretendientes son sujetos intruídos y que han hecho viajes que les permitieron adquirir conocimientos prácticos. Que el dn. Pedro Sinnot es hijo de un Director fabricante de jabón, y que el que proyecta fabricar fue reconocido y aprobado por la comisión del Consejo y de la Sociedad de Madrid por personas de las más inteligentes ẹ la materia. Además de esto, sabe que el dn. Roque Vico es de una familia de bastante caudal y acreditada en este Reyno. Y esto es lo único que puede informar del saber y facultades de los dos interesados, no siéndole posible dar más extensión a esta noticia, a no sujetarlos a nuevos exámenes y pruebas (...)

La Sociedad tendrá la mayor satisfacción en haber acertado en su Informe para concurrir, en esto y en cuanto le sea posible, al establecimiento de esta y otras fábricas en que tanto se interesa este Reyno. Sírvase V.E. elevar estos sentimientos hasta el Trono, mientras ella ruega a Nuestro Señor prospere a V.E. muchos años.

Casas Consistoriales de la Ciudad de Santiago, a 13 de julio de $1785^{\prime \prime 6}$.

Por lo que concierne al dictamen evacuado por la Sociedad Económica Matritense de Amigos del País, hace destacar como aspectos positivos que podrían derivarse de la proyectada fábrica los siguientes:

1) El obvio que Galicia podría proveer de todo el sebo y grasa necesarias para el mantenimiento de una factoría de cuatro calderas, mayormente cuando "ya se ha comenzado a traerse los sebos de Buenos Aires en los paquebotes correos de Su Magestad".

2) Bajo el prisma comercial, la población gallega se surte preferencialmente del jabón de Andalucía y en muy corta porción del que se elabora en los contornos de Madrid; y no es menos de ponderar el frecuente y perjudicial consumo que se hace del mal jabón de Portugal, tráfico que genera la extracción de dinero en beneficio del país vecino. Por consiguiente, estiman los informantes que el precio de la manufactura elaborada en Betanzos saldría más barata, por la ventaja de producir el jabón de sebo más cantidad que el de aceite ${ }^{37}$.

${ }^{36}$ A.H.N., Estado, leg. cit., exp. cit., doc. 13 jul. 1785.

37 Pues, se asevera, "cada libra de sebo, siendo reciente y bien acondicionado, dará cerca de dos libras y quarterón de buen jabón duro, y algo más de jabón blando o melado, que es el que comúnmente se gasta en muchas partes". 
3) Por lo que respecta a la concesión del privilegio de facilitar a los empresarios un anticipo de fondos a cuenta de los espolios y vacantes de la Mitra compostelana, el dictamen de la S.E.M.A.P. fue del parecer de que "no puede haber reparo, pues a la verdad esto no vendría a ser más que un préstamo sin intereses".

Por el contrario, la Matritense en modo alguno se mostró propicia a la concesión por la Corona de dos valiosas y muy singulares franquicias. La primera atinente a que la fábrica se instalase en el edificio construído para servir de futura sede al Archivo del Reino de Galicia. Sobre este punto el dictamen decía así: "No hay clases de fábrica que requiera edificio más sencillo y menos costoso que la del jabón, pues con unos tinglados en que guardar las cenizas y acomodar las tinas de las lejías, y un simple cubierto, alto, y con respiradores por todos lados, debajo del cual están las calderas, ya se tiene el edificio necesario (...) Sería doloso emplear en semejante uso una caśa que, según exponen estos mismos interesados, ha costado más de 800.000 reales de vellón, y que para acomodarlo a fabricación de jabón podría exigir mucha mayor cantidad que la necesaria para establecer de pié toda la manufactura".

La Matritense expresó también su rotunda oposición con respecto al nombramiento que Vico pretendía de ser Corregidor de la ciudad de Betanzos, "por el tiempo del agrado de S.M. para establecer y adelantar la manufactura...". Y también a que se le dispensara la jurisdicción privativa de la proyectada fábrica; pues tan novedosa e insólita franquicia, la de "ser fabricante y tener jurisdicción privativa sobre su fábrica, no es cosa que hasta ahora se haya visto ni sea capaz de verse, a menos que se transtorne nuestra constitución" 38 .

La resolución final adoptada por el Real Consejo sobre las pretensiones de Sinnot y Vico ha sido del tenor siguiente:

1) Por concurrir las circunstancias de "ser de superior calidad el jabón de la fábrica que se promete erigir, y bastante considerable la baja de su precio", se concede a dichos empresarios "las franquicias regulares que ordinariamente" se dispensan a todas las fábricas, bajo la obligación de introducir "la enseñanza de un cierto número de aprendices u oficiales en cada un año, pasados los dos primeros de su establecimiento".

2) Se les franquean 80.000 reales de los espolios y vacantes del Arzobispado de Santiago, "bajo la seguridad y fianza que prometen para su reintegro, asignándoles unos plazos cómodos y de alguna dilación para el pago".

3) Contrariamente, y de conformidad al criterio expuesto por la Economica Matritense, determina la real cédula que los dos restantes privile-

${ }^{38}$ A.H.N., Consejos, leg. 1340, exp. cit., fols. 15-18. 
gios pretendidos -el de entregarles "la casa de bastante importe" construída en Betanzos para sede del proyectado Archivo de Galicia y la designación como Alcalde de aquella ciudad a favor de Vico -"no se deben conceder y sí expresamente denegárselos"39

Como último y único dato disponible acerca de esta planeada industria, sabemos que, en junio de 1785, pendía la cuestión relativa a la seguridad y fianzas ofrecidas por Vico. Como socio capitalista, éste elevó entonces recurso ante el ministerio de Hacienda en súplica de ser exonerado de las garantías requeridas. Pues "no entrando en su poder -afirma- caudal alguno de los 100.000 reales pedidos a los espolios y vacantes de Santiago, hasta su efectivo reintegro, sólo quedará de su precisa obligación la actividad, el celo y los buenos progresos, que es el único objeto a que aspira en servicio de S.M. y del bien común de Galicia" ${ }^{40}$. Es de presumir, pues, haya sido ésta la causa primordial de que no pudiera llevarse a efecto la planificación de la factoría.

\section{Proyecto de establecer fábricas en La Coruña, Ferrol y Santiago (1794)}

Para concluir estos apuntes sobre un capítulo desconocido de la historia industrial de Galicia, es preciso referirnos al intento promovido en 1794 por Mariano Cabot, Juan Antonio Marcó y Antonio Trelles, en orden a promocionar, en cualquiera de las ciudades de La Coruña, Ferrol y Santiago, la fabricación de jabón.

Estos tres hombres de negocios elevaron una representación a la Junta de Comercio en demanda de permisividad regia para emprender la elaboración de "diferentes clases de tejidos lisos y labrados, hilos para coser blancos y de colores, jabonería, calcetes e indianas..." Y solicitaron a tal efecto que sus futuras fábricas fuesen "admitidas bajo la real protección" y gozaran de las gracias concedidas a otras de sus respectivas clases ${ }^{41}$.

Se acordó por la Corona otorgar facultad a los citados empresarios para poder eregir su proyectada fábrica de jabón. Con tal motivo se remitió por el ministro de Hacienda a las autoridades de Rentas de Galicia un despacho puntualizando la normativa por la que habría de regirse la proyectada factoría en su funcionalidad, tributación al fisco y giro comercial. Reproducimos del mismo los siguientes pasajes:

"Como en ese Reyno no ha habido hasta ahora fábrica alguna de jabón de que tengamos noticia, sino que se ha surtido siempre de las establecidas en la provincia

${ }^{39}$ A.H.N., Ibid., leg. cit., fols. 23-24.

${ }^{40}$ A.H.N., Ibid., leg. cit., doc. 15 jun. 1785.

41 A.G.S., C. S. Hacienda, Registros, lib. 242, fol. 135. 
de Sevilla y en otras de Castilla, no se han comunicado las órdenes que rigen para la exacción de sus respectivos derechos. Estos se reducen a que, siendo las fábricas de jabón blanco y tomado conocimiento de sus regulares productos, se deben ajustar por todos los derechos que en ellas se causan y son: los de millones del aceite que consumen en la fabricación de jabón al respecto de tres reales por arroba; los de alcabalas y cientos del jabón que venden al respecto del 4 por cien; y el derecho de 4 maravedíes en libra del mismo jabón que debe exigirse al pié de la fábrica.

Cuando las fábricas son de jabón duro, causan los mismos derechos (...) Por consecuencia, si las fábricas de jabón que se van a establecer por los expresados sujetos fuesen de la clase del blanco, se deben tomar los correspondientes conocimientos para ajustarlas para todos los referidos derechos, y si fuesen del duro administrarlos en Fieldad hasta que haya lugar de que pase alguno de los visitadores de fábricas a medirlas o se disponga esto por otro medio (...)

Las calderas de jabón duro deben tener sangrados por donde se purifiquen las lejías. Y no teniéndolo no se deben permitir, y se pueden denunciar por todos los Dependientes de Rentas, formando la correspondiente sumaria, y pasándola a los Subdelegados de la Junta General de Comercio"42.

Lamentablemente, esta tentativa de Cabot, Marcó y Trelles, al igual que las otras anteriormente expuestas, tampoco lograría efectividad alguna. Vemos, pues, cómo concluiría el siglo XVIII sin conseguirse elaboración alguna de un producto saponificado en Galicia. Las diversas tentativas abocaron en fracaso. Apenas fue excepción la fábrica pontevedresa de Salcedo, pues ésta tuvo muy pocos años de vida, y muy dificilmente alcanzaría virtualidad práctica en orden a un decoroso rendimiento comercial.

${ }^{42}$ A.H.P., Rentas, leg. 882, doc. 15 jul. 1794. 